\title{
La dimensión política del mal radical y de la banalidad del mal en el pensamiento de Hannah Arendt. Continuidades y divergencias
}

\author{
The political dimension of radical evil and the banality of evil \\ in Hannah Arendt's thought. Continuities and divergences
}

MARÍA WAGON'

\begin{abstract}
Resumen: El mal radical y la banalidad del mal son las dos formas en que Arendt ha catalogado al mal totalitario en distintas etapas de su obra. El objetivo del presente trabajo es abordar las diferentes concepciones arendtianas del mal desde la perspectiva política con el fin de determinar si existen continuidades o si, por el contrario, hay un cambio abrupto en el pensamiento de Arendt. La dificultad que debe enfrentarse es que el problema del mal y las reflexiones sobre lo político no son temas abordados por Arendt de forma directa sino que son contenidos transversales que deben rastrearse en la totalidad de su obra. Se concluye que el mal radical y el mal banal no son nociones excluyentes sino que remiten a dos niveles diferentes, uno más general y estructural y el otro vinculado con el comportamiento de los individuos dentro de las estructuras gubernamentales estudiadas.
\end{abstract}

Palabras Clave: mal radical; banalidad del mal; dimensión política; acción; juicio; espacio público.

Abstract: Radical evil and the banality of evil are the two ways in which Arendt has cataloged totalitarian evil at different stages of his work. The aim of this paper is to approach the different Arendtian conceptions of evil from a political perspective in order to determine whether there are continuities or whether, on the contrary, there is an abrupt change in Arendt's thinking. The difficulty that must be faced is that the problem of evil and the political question are not issues addressed by Arendt directly but are transversal contents that must be traced in the totality of his work. It is concluded that radical evil and the banality of evil are not mutually exclusive notions but rather function as expressions that refer to two different levels, one more general and structural and the other linked to the behavior of individuals within the government structures studied.

Key Words: radical evil; banality of evil; political dimension; action; judgment; public space.

Cómo citar: Wagon, M. (2019). La dimensión política del mal radical y de la banalidad del mal en el pensamiento de Hannah Arendt. Continuidades y divergencias. Cuadernos Filosóficos 16. https://doi.org//0.35305/cf2.vil6.62

Publicado bajo licencia Creative Commons Atribución-SinDerivadas 4.0 Internacional [CC BY-ND 4.0] 


\section{Introducción}

El problema del mal es uno de los cuestionamientos clave del pensar filosófico en general y de la teoría política arendtiana en particular. En la actualidad, los acontecimientos de la realidad mundial con su constante actualización de la violencia, interpelan y ponen en cuestión las teorías tradicionales sobre el mal, sus fundamentos y sus alcances, y exigen nuevos abordajes y reflexiones. Arendt $(1998)^{2}$ realiza una primera caracterización del mal acaecido durante el régimen totalitario nazi catalogándolo de mal radical, un mal sin precedentes en la historia occidental que excede las categorías tradicionales por medio de las cuales se había intentado comprenderlo. Esta concepción del mal es posteriormente reemplazada por la noción de banalidad del mal, una nueva caracterización del mencionado fenómeno realizado por la autora luego de su asistencia al juicio realizado a Eichmann en Jerusalén. Arendt (2003b) ${ }^{3}$ se enfrenta con el hecho de que el criminal al que se estaba procesando no podía ser encuadrado dentro de la caracterización tradicional del individuo malvado. Eichmann no era un monstruo ni un ser diabólico sino, por el contrario, un ciudadano común, obediente de las leyes, que por mera irreflexión y en aras de una obediencia ciega a la autoridad, formó parte activa en la puesta en efecto de los peores crímenes acaecidos en la historia.

En el ámbito crítico proliferan los estudios que analizan la complementariedad o incompatibilidad de ambas concepciones del mal y se mantienen, aún en la actualidad, posiciones divergentes al respecto. Dichos abordajes críticos suelen llevar a cabo análisis multidimensionales del problema del mal en el marco del pensamiento arendtiano o, en algunos casos, no especifican desde qué perspectiva se aborda la temática ni qué alcance tienen las conclusiones a las que se arriba. En este trabajo se pretende estudiar los conceptos de mal radical y banalidad del mal desde la dimensión política con el objetivo de poder determinar el tipo de relación (de exclusión o complementariedad) que mantienen dichas nociones en el marco del pensamiento arendtiano. Teniendo en cuenta la mencionada delimitación, debe tenerse en presente que las conclusiones alcanzadas en esta investigación remiten exclusivamente a la dimensión política. En otra palabras, la relación de exclusión o

2 El trabajo original se publicó en 195 I con el título The Origins of Totalitarianism (OT), edición que fue ampliada y reeditada en los años 1958, 1967-1968. En esta investigación se trabajará con la traducción al castellano realizada por Guillermo Solana de la tercera edición del texto.

3 La primera edición del libro es del año 1962, fue titulada Eichmann in Jerusalem: A Report on the Banality of Evil (E). En este trabajo se utilizará la edición en inglés del año 1964 y la edición en español del 2003, traducción al castellano de Carlos Ribalta. 
complementariedad que pueda rastrearse en este trabajo entre el mal radical y la banalidad del mal se predica solo en lo que respecta a la dimensión política de análisis. Quedará postergado para futuras investigaciones, entonces, el abordaje de la misma problemática pero desde la dimensión moral, jurídica, etc. A tal efecto, en un primer momento se expondrán brevemente las características generales de ambas concepciones del mal. Luego se realizará un recorrido sobre la concepción arendtiana de lo político con un especial detenimiento en las nociones de acción, juicio y espacio público, categorías que serán utilizadas con posterioridad en el análisis de la dimensión política del mal en $O T$ y EJ. Cabe aclarar que si bien las categorías mencionadas fueron desarrolladas por Arendt con posterioridad a la publicación de $O T$, se considera que ya en dicha obra es posible derivar consecuencias respecto de las mismas, aunque en sentido negativo, es decir, desde su anulación. Por último, se retomará lo analizado para poder determinar si, desde el plano político, las nociones de mal radical y banalidad del mal poseen puntos en común $y$, por lo tanto, pueden ser concebidas como conceptos complementarios o si, por el contrario, las observaciones arendtianas respecto de cada concepción del mal reflejan la incompatibilidad entre ambas concepciones.

\section{Mal radical y banalidad del mal: breve exposición}

\section{I. Mal radical}

La concepción del mal radical en Arendt remite a una denominación kantiana que la autora resignifica. Su comprensión se ve dificultada por el hecho de que son escasas las referencias y aclaraciones arendtianas al respecto, por lo que sus notas distintivas deben ser rastreadas a lo largo de su obra y deducidas de sus análisis sobre diferentes tópicos vinculados. Siguiendo la caracterización propuesta por Di Pego (2007), se puede afirmar que el mal radical, bajo la óptica arendtiana, presenta las siguientes seis características: (I) los campos de concentración y exterminio propios del totalitarismo cumplían con el objetivo de eliminar las características humanas de los internados antes de eliminarlos físicamente. Era eliminado, también, todo rastro que pudiese testificar sobre su existencia y su posterior deceso. En este sentido, el mal radical consiste en la eliminación total del ser humano, relegándolo al olvido durante su vida así como también después de su muerte. (II) Arendt observa que bajo las medidas llevadas a cabo por los gobiernos totalitarios se logró eliminar la espontaneidad humana, es decir, la capacidad inherente a los seres humanos de comenzar imprevisiblemente una nueva cadena de acontecimientos. El mal radical consistió en transformar la capacidad humana para la acción en meras reacciones ante determinados estímulos. (III) Las mencionadas características traen 
aparejado como consecuencia directa el hecho de volver superfluos a los seres humanos, es decir, transformarlos en individuos carentes de valor, reemplazables e insignificantes. (IV) El mal radical es imperdonable, $(\mathrm{V})$ incastigable y $(\mathrm{VI})$ sus motivos son incomprensibles. A estas características destacadas por Di Pego (2007) cabría agregar (VII) el rol preponderante que tuvo el terror en los regímenes totalitarios, el cual es una característica esencial del mal radical. Y, finalmente, (VIII) el abandono de los criterios utilitarios y de la racionalidad instrumental como fundamentos del mal radical.

A modo de síntesis, el mal radical se caracteriza por su no adecuación a las categorías tradicionales con las que se ha analizado históricamente el mal. Este tipo de mal no puede ser explicado por motivos ni intereses personales de ningún tipo sino que, por el contrario, sus móviles resultan incomprensibles. Una de sus notas distintivas es su intento de convertir a la humanidad en seres superfluos, es decir, en individuos prescindibles, intercambiables, incapaces de ser espontáneos. Esta superfluidad afecta a víctimas y victimarios. Dicha superfluidad se nutre del desarraigo, pues necesita tanto de la destrucción del mundo concebido como una creación humana estable así como de la anulación de los lazos intersubjetivos que unen a los individuos entre sí y que crean el sentimiento de comunidad. En este sentido se puede afirmar que la soledad es otra de las notas esenciales del mal radical. También lo es el terror, el cual ya no es concebido desde un perfil utilitario, es decir, como medio para conseguir determinado fin, sino que se vuelve un fin en sí mismo. Arendt sostiene que la aspiración a la dominación total propia de los regímenes totalitarios atraviesa tres etapas, a saber: la anulación de la persona jurídica, la anulación de la persona moral y, por último, la anulación de la individualidad e identidad del individuo, una vez alcanzado este objetivo todo se vuelve posible.

\subsection{Banalidad del mal}

La noción de mal radical ya no es retomada por Arendt en obras posteriores a $O T$, quien, salvo en la carta citada con anterioridad, no da mayores explicaciones sobre la no atinencia del adjetivo "radical" en lo que respecta al mal totalitario. Young-Bruehl (1993, p. 469) menciona que a partir del abandono del concepto de mal radical Arendt se liberó de una larga pesadilla, pues ya no tenía que vivir con la idea de que monstruos asesinos habían pergeñado la muerte de millones de personas. Desde el ámbito crítico muchos han relativizado la afirmación de la autora respecto al cambio que sufriera su concepción del mal. Por un lado, se sostiene que las nociones de mal radical y banalidad del mal son complementarias en tanto responden a diferentes aspectos del mal (Bernstein, 2004; Pendas, 2007; Hilb, 20I5, entre otros) y, en este 
sentido, pueden coexistir. Por otro, se afirma que la acepción del adjetivo radical con el que Arendt define al mal en su carta a Gershom Scholem ${ }^{4}$ difiere de la que utiliza en $O T$ (Bernstein, 2004). En la mencionada carta estaría tomada en sentido estrictamente etimológico en cambio en el capítulo "Dominación total" de $O T$ se lo define en relación con la noción de superfluidad.

Ahora bien, estas consideraciones no son aceptadas por toda la masa crítica pues hay quienes (Bernauer, 1985; Villa, 1999) brindan algunas posibles razones que explicarían el abandono, por parte de Arendt, del concepto de mal radical y afirman la incompatibilidad del mencionado concepto respecto del de la banalidad del mal si se los aborda a ambos filosóficamente. Villa (1999) afirma que Arendt dejó de lado la categoría de mal radical porque era conciente del dejo teológico que dicha concepción del mal traía aparejada. A criterio de Villa, el mal puede poseer profundidad metafísica solo en un marco teológico que postule la existencia de fuerzas transhumanas que breguen por el bien y el mal. Young-Bruehl (1993, p. 329) sostiene, en concordancia con Villa, que el concepto de mal radical que propone Arendt detenta un matiz teológico, pero lo vincula con la noción de superfluidad y con la aspiración de los hombres a la omnipotencia que, en las religiones monoteístas, es prerrogativa divina. Agrega que dicho concepto remite a las teorías gnósticas o maniqueas que postulan la existencia de un bien y un mal primigenios que luchan por prevalecer en el cosmos y cuya batalla se replica en cada ser humano. Arendt rechaza esta postura y adhiere a la que fuera su alternativa principal en el pensamiento occidental, a saber: el mal es ausencia de bien, es decir, el mal entendido como privación. Sin embargo, explica la naturaleza privativa del mal en términos seculares.

En su libro EJ Arendt no hace ninguna alusión al mal radical e introduce el concepto de banalidad del mal. Para la autora, lo alarmante del caso Eichmann fue llegar a la conclusión de que las acciones terribles por las que fue juzgado no fueron cometidas por un ser monstruoso sino que, por el contrario, fueron realizadas por alguien que se encontraba muy lejos de comportarse como un ser demoníaco (Canovan, 1992, p. 160). Con posterioridad, en las lecciones que Arendt dicta entre 1965 y 1966 (2007a) sobre las cuestiones morales, retoma la idea de que el peor de los males que puede existir no es radical, en el sentido de que no tiene raíces, por lo que tiene la capacidad de extenderse con mucha rapidez y de manera ilimitada.

4 Gershom Scholem era un estudioso judío nacido en Alemania y luego radicado en Israel, fue conocido por su erudición respecto de la mística judía. Arendt y él se conocieron gracias a un amigo en común, Walter Benjamin. Luego de la publicación de EJ Scholem le escribe una carta a Arendt manifestándole su total desacuerdo respecto de su nueva concepción del mal (banalidad del mal). La pensadora le responde diciéndole que ya no cree que el mal pueda ser radical y reafirma su cambio de postura en lo que al problema del mal respecta. 
Cuando Arendt utiliza la noción de "raíz" o "raíces" lo hace en el sentido de profundidad y arraigo en la reflexión. El mal sin límites encuentra terreno fértil allí donde la facultad de pensar ( $y$ de recordar) está ausente y, por consiguiente, también lo están las raíces que limitan las posibilidades de obrar. Aquellos individuos que no ejercen su capacidad de pensar se dejan arrastrar por los acontecimientos, deslizándose por la superficie de los mismos, y no penetran nunca hasta la profundidad reflexiva de la que, como seres humanos, son capaces.

En el Tercer Reich hubo pocas personas que acordaran plenamente con los crímenes realizados por el régimen nazi en su último período, sin embargo, muchos estuvieron dispuestos a cometerlos. Arendt se pregunta, entonces, qué diferencia hubo entre estos individuos y aquellos pocos que se negaron a colaborar bajo toda circunstancia, tanto en el ámbito privado como en el público. La respuesta que encuentra es que quienes no participaron ni colaboraron fueron aquellos individuos cuya conciencia no funcionó automáticamente (a diferencia de la de los "ciudadanos respetables" que cambiaron un código moral por otro) sino que juzgaron por sí mismos. Estos individuos, en muchos casos, prefirieron morir a obedecer órdenes criminales porque fueron conscientes de que, de lo contrario, no podrían seguir viviendo en paz consigo mismos.

A modo de síntesis, el mal banal es un nuevo tipo de mal que se caracteriza por su falta de reflexión y de compromiso ideológico. En esto radica su peligrosidad y su gran poder de propagación. En la figura de Eichmann Arendt vio materializada una capacidad infinita para llevar a cabo los males más horrendos por los motivos más fútiles y nimios. De esto deduce que el no ejercicio de la facultad de pensamiento inherente a todo ser humano puede llevar a la humanidad a realizar el peor de los males sin inmutarse por ello. En el caso de Eichmann, lo llevó a priorizar su trabajo, su carrera profesional, sin reparar en que su obrar lo obligaba a convivir con un asesino.

\subsection{Dimensión política}

Una de las primeras cuestiones que deben tenerse presentes a la hora de abordar la concepción arendtiana de lo político es que dicha noción no permanece inmutable a lo largo de la trayectoria académica de Arendt sino que sufre modificaciones que han dado lugar a diferentes abordajes críticos. Lo político arendtiano acontece bajo condiciones de pluralidad e igualdad. En La condición humana ( $C H)$, la categoría que lo representa es la acción, en La vida del espíritu (VE), lo es la facultad humana del juicio. A continuación se expondrán de manera breve las cuestiones más relevantes de las categorías de acción, juicio y espacio público, a los 
efectos de contar con una referencia clara y concisa de las mismas que permita un abordaje profundo de la problemática política del mal totalitario.

\section{Acción}

Arendt, en $C H$ (2009), se aboca al análisis de la noción de vita activa, concepto que alude a tres actividades propias del género humano: labor, trabajo y acción. La labor es definida como la actividad propia del proceso biológico del cuerpo humano por medio de la cual se logra la supervivencia. La condición humana de la labor es la vida. Por trabajo la autora entiende aquella actividad que le proporciona al individuo un mundo artificial de cosas. En tal sentido, el trabajo no está inmerso en el ciclo natural de la vida del hombre, sino que lo trasciende en la durabilidad del producto de su actividad. Arendt no reduce el mundo creado por el trabajo a su utilidad sino que lo concibe como "la verdadera morada humana (...), interpuesta no solo entre ser humano y naturaleza, sino (...) entre uno y otro ser humano, (...) de manera que al mismo tiempo separa y une" (Jonas, 2000, p. 31). La condición humana del trabajo es la mundanidad. Por último, la acción es entendida como la actividad que acontece entre los hombres y que no requiere de la mediación de cosas o de materia alguna. Su condición humana es la pluralidad, condición indispensable de toda vida política. "Estas tres actividades y sus correspondientes condiciones están íntimamente relacionadas con la condición más general de la existencia humana: nacimiento y muerte, natalidad y mortalidad" (Arendt, 2009, p. 22).

En la propuesta política arendtiana la acción es la única actividad exclusivamente humana que requiere necesariamente de la presencia de otros para ser llevada a cabo, con lo cual Arendt establece una estrecha relación entre el actuar y el estar juntos. Los hombres se diferencian entre sí mediante el discurso y la acción, atributos que se fundamentan en la condición de la pluralidad que alberga en su interior la igualdad y la distinción ${ }^{5}$. Para Arendt, es el discurso compartido el que le otorga realidad a los hechos, es mediante la materialización de la acción y el discurso que los seres humanos se diferencian unos de otros y se igualan en su pluralidad. Mediante la palabra y la acción el ser humano se inserta en el mundo y, por medio de la acción, además, inicia una cadena nueva de acontecimientos. Es en la acción humana donde Arendt ancla la idea de que los hombres no han nacido para morir sino para iniciar algo nuevo en el mundo.

5 Arendt (1997) distingue entre dos tipos de pluralidad, dos modos diferentes del estar juntos: entre seres humanos iguales entre sí, de donde surge la acción; y entre uno y su sí mismo, relación de la que surge el pensar. 
La acción de la que es capaz el hombre trae ínsita la noción de natalidad, el discurso, por su parte, a través de la pluralidad humana expresa la distinción y singularidad de cada individuo. A su vez, la acción requiere del discurso para completarse puesto que es por medio de la palabra que se visualiza el sujeto actuante. La acción y el discurso son frágiles en relación con los procesos y productos de la labor y el trabajo y requieren de la recepción de otros que los vean, los oigan y los recuerden (Birulés, p. 2002). A diferencia de la materialidad de los procesos y productos de la labor y del trabajo, la acción y el discurso no dejan tras de sí ningún rastro concreto sino que requieren de los otros, de su memoria y sus narraciones, para poder perdurar en el tiempo.

\section{Juicio}

Arendt falleció justo antes de comenzar a escribir la tercera y última parte de su obra sobre las facultades del espíritu humano, $V E$, en la cual tenía previsto abordar el juicio como facultad autónoma junto al pensamiento y la voluntad. Por esta razón, reflexionar sobre la concepción arendtiana del juicio implica necesariamente rastrear a lo largo de su obra todos sus aportes al respecto $y$, fundamentalmente, hacer hincapié en las conferencias sobre Kant que Arendt dictara en la New School for Social Research durante el otoño de 1970, publicadas póstumamente como Conferencias sobre la filosofía política de Kant. La relevancia de estas conferencias radica en el hecho de que en ellas la pensadora reflexiona sobre la Crítica del Juicio kantiana y reinterpreta su contenido en clave política.

En lo que respecta a la concepción de la facultad del juicio de Arendt, Benhabib (1996, p. 173) sostiene que es desconcertante debido, principalmente, a tres conjuntos de afirmaciones que la pensadora desarrolla al respecto en distintas obras y que se encuentran en tensión entre sí. En primer lugar, en la introducción al primer tomo de $V E$, Arendt menciona que su interés por las facultades de la mente (pensamiento, voluntad y juicio) se fundamenta en dos cuestiones, a saber: el juicio a Eichmann en Jerusalén y, por otro lado, su interés por investigar la vita contemplativa, es decir, la contraparte de la vita activa, la cual había sido el centro de su análisis en $\mathrm{CH}$. Arendt se distanció del abordaje tradicional del problema del mal al acuñar la noción de banalidad del mal y sostener que Eichmann no era un monstruo sino un ser cuya cualidad principal era la irreflexión. Esto la llevó a preguntarse si existe una relación entre la facultad del juicio entendida como aquella que le permite al individuo distinguir entre el bien y el mal, entre lo bello y lo feo, y la facultad del pensamiento. Benhabib (1996, p. 174), en este 
punto, pone el acento en que esta caracterización de la facultades de juicio y pensamiento responde a una concepción moral de las mismas.

Por otra parte, continúa Benhabib (1996, p. 174), en el "Postscriptum" del primer tomo de $V E$, "Pensamiento", deja de lado la concepción moral del juicio y pasa a concebirlo como una facultad retrospectiva cuya función es extraer significado del pasado, es decir, como la facultad propia del arte de narrar historias. En este cambio se puede observar, como señalara Beiner (2003), cómo Arendt pasa de poner el acento en el actor que juzga para actuar para interesarse en el espectador que juzga para extraer significado del pasado. Por último, Benhabib (1996, p. 175) menciona que la concepción arendtiana del juicio no solo vacila entre la perspectiva moral del actor y la retrospectiva del espectador, sino que existe una perplejidad filosófica más profunda en lo que respecta al estatus otorgado al juicio en su obra. Dicha perplejidad radica en el intento arendtiano por unir la concepción aristotélica del juicio concebido como un aspecto de la phronesis y la concepción kantiana que entiende el juicio como la facultad del pensamiento ampliado o del pensamiento representativo.

\section{Juzgar en situaciones críticas}

Beiner (2003) reflexiona sobre el papel otorgado por Arendt a la facultad de juzgar en los momentos históricos críticos. En relación con esto, lo primero que apunta es que el pensamiento cobra relevancia política porque solo aquellos que lo ejerzan críticamente evitarán ser arrastrados por la irreflexividad de la opinión pública. Para fundamentar lo expuesto se apoya en una cita kantiana en la que Kant si bien establece una distinción entre el pensamiento y el juicio (el primero opera con las representaciones de cosas ausentes y el segundo se ocupa de particulares siempre presentes), propone, a su vez, una relación estrecha entre ambas facultades. El juicio es la manifestación del pensamiento en el mundo de apariencias, es su realización. La consecuencia relevante de esta afirmación es que se pueden prevenir catástrofes gracias a la manifestación del "viento del pensar" que permite distinguir el bien del mal.

Respecto a la concepción de la facultad del juicio en el pensamiento arendtiano, Beiner menciona que opera siempre con particulares en el mundo de apariencias. Estos particulares son aprehendidos mediante su subsunción a un universal. Ahora bien, cuando estos universales son concebidos como reglas y hábitos rígidos surge el peligro de dejar pasar ciertos matices inherentes a la realidad fenoménica que se somete a juicio. Para poder distinguir las diferencias en los acontecimientos, es decir, percibir la realidad por fuera de las reglas rígidas a las que el 
individuo se encuentra acostumbrado, es necesaria una particular cualidad del juicio. "En tiempos de crisis política, será más difícil pillar desprevenidos a quienes tienen gusto y distinguen en las cosas lo bello de lo feo, el bien del mal (Beiner, 2003, p. 195). La pertinencia política del pensamiento radica en su relación con el juicio.

\section{Espacio público}

Arendt (2009) define lo público como aquello que aparece en un mundo compartido y, por esto, puede ser visto y oído por otros. La acción, solo posible en la esfera pública, requiere, a los efectos de su aparición, de la visibilidad que únicamente le brinda dicho espacio. Una de las características principales del espacio público es su carácter efímero, pues no sobrevive al movimiento que lo origina, es decir que, ni bien los hombres se dispersan o suspenden su actividad, desaparece. Su esencia radica en la acción y el discurso. Arendt agrega que el espacio público no es homogéneo y se encuentra potencialmente allí donde los individuos se reúnen, es decir que no se da necesariamente ni para siempre. El espacio público es el lugar donde se construye la igualdad entendida en un doble sentido, a saber: como isonomía (igualdad ante la ley) y como isegoría (igualdad para la acción).

El poder que genera la unión de palabra y acto es lo que mantiene la existencia de la esfera pública. "[E]l poder surge entre los hombres cuando actúan juntos y desaparece en el momento en que se dispersan" (Arendt, 2009, p. 223). A su vez, Arendt vincula el espacio público no solo con la acción y el discurso, como se expuso, sino también con la noción de mundo, la cual en su análisis de la vita activa se relaciona con el concepto de trabajo. El mundo de cosas que se encuentra en medio de los seres humanos, los une y los separa al mismo tiempo ${ }^{6}$. Canclini destaca que la noción de espacio público vinculada a la de mundo remite a la necesidad de permanencia y durabilidad de las relaciones humanas (2016, p. 169).

Rabotnikof (2005), en su estudio sobre las diferentes concepciones del espacio público, realiza una doble clasificación, a saber: la concepción procedimental del espacio público y la fenomenológica. Dentro de esta clasificación ubica a Arendt en la concepción fenomenológica cuyo principal interés radica en las formas en que el poder se constituye y aparece ante los

6 Arendt utiliza la metáfora de la mesa para referirse al espacio público: "Vivir juntos en el mundo significa en esencia que un mundo de cosas está entre quienes lo tienen en común, al igual que la mesa está localizada entre los que se sientan alrededor; el mundo, como todo lo que está en medio, une y separa a los hombres al mismo tiempo" (Arendt, 2009, p. 62). 
hombres ${ }^{7}$. Benhabib (1993, p. 30), respecto a la concepción arendtiana del espacio público en el marco de su teoría sobre el totalitarismo, sostiene que puede observarse un cambio de enfoque si se compara lo expuesto por Arendt en $O T$ con su posterior análisis de dicha noción en $\mathrm{CH}$. "El contraste entre estos modelos de espacio público puede ser captado a través de términos como 'agonista' versus 'asociativo"' (Benhabib, 1993, p. 31). El primer modelo de espacio público, el agonista, es desarrollado por Arendt en $\mathrm{CH}$ y remite a un espacio de aparición competitivo en el cual se despliegan y comparten con los demás la grandeza, tanto moral y política, como el heroísmo. En este tipo de espacio se lucha por el reconocimiento y la aclamación, la colaboración, por su parte, es dejada de lado es pos de la competencia. El modelo asociativo de espacio público, en cambio, emerge siempre que los individuos actúen en concierto, es decir que no remite a un espacio topográfico concreto sino a un modo de relación entre los hombres, y es el ámbito en el cual, según Arendt, puede surgir la libertad (Benhabib, 1993, p. 32). Los espacios topográficos "se convierten en espacios públicos en tanto se vuelven 'sitios' de poder, de una acción común coordinada mediante el lenguaje y la persuasión" (Benhabib, 1993, p. 32). Si bien ambos modelos de espacio público, según Benhabib (1993, p. 32), están presentes en la obra arendtiana, el modelo asociativo se encuentra menos analizado $y$, a diferencia del modelo agonista, remite a un espacio abierto en el cual no se encuentran determinados ni el quién de los participantes ni el qué del debate. Benhabib (1993, p. 33) concluye que el legado dejado por Arendt, tanto en su concepción del modelo de espacio público agonista como asociativo, no siempre se ha cohesionado de manera armoniosa en sus análisis sino que la tensión entre ambos se revela a lo largo de toda su obra.

En una obra posterior, Benhabib (1996, p. 20I) retoma el análisis de las funciones del espacio público en el marco de la concepción política arendtiana. Afirma que en la vinculación que Arendt establece entre el espacio público y el espacio de aparición tiene en mente un modelo de interacción humana directa que supone un cierto grado de homogeneidad y la convergencia de los individuos implicados en un ethos compartido ${ }^{8}$. A esta función del espacio público la denomina holística. "Public space, according to this view, is a space in which a collectivity becomes present to itself and recognizes itself through a shared interpretive repertoire" (Benhabib, 1996, p. 201). A su vez menciona que la noción arendtiana de espacio público tiene, también, una función epistémica que cobra relevancia en el intento que realiza

7 Dentro de la concepción fenomenológica del espacio público Rabotnikof menciona que hay otra rama, cuyo representante principal es Luhmann, que se centra en la forma en que ciertos temas son determinantes a la hora de la toma de decisiones políticas.

8 Benhabib aclara que dicha convergencia en un ethos común no debe interpretarse como unanimidad en las interpretaciones. 
Arendt por distinguir lo político de la social. El proceso de lucha público-político debe transformar el interés propio en un interés público o común compartido ampliamente. Benhabib (1996, p. 202) concluye que los modelos holístico y epistémico de espacio público son clave para cualquier teoría de legitimidad democrática, ya sea antigua o moderna, que sostiene que el gobiernos es, esencialmente para el pueblo, a través del pueblo y por el pueblo.

Sahui Maldonado, por su parte, en lo que respecta a la noción de espacio público, ofrece una interpretación que lo vincula hasta casi identificarlo con el concepto de mundo. Aclara que dicho concepto, en la concepción arendtiana, no debe confundirse con la naturaleza o el cosmos. El mundo es el lugar de aparición de los seres humanos, es el espacio público en donde los individuos se encuentran con ellos mismos y con los demás (Sahui Maldonado, 2002, p. 243). Este espacio es eminentemente político y es el escenario donde se despliega la trama de las relaciones humanas. La política, para Arendt, es entendida en tanto relación que acontece en el entre que al mismo tiempo une y separa a los seres humanos. De las tres actividades inherentes a la vita activa anteriormente mencionadas, solo la acción es propia del espacio de publicidad, la labor y el trabajo pertenecen a la esfera privada. En otras palabras, la esfera pública en tanto espacio de aparición en el que se manifiestan el discurso y la acción es una esfera de igualdad entre seres desiguales. Los procesos que se inician por medio de la acción humana son impredecibles $y$, en este sentido, incontrolables. El hombre carece de la capacidad de deshacer aquello que realizó en el mundo y de anticipar las consecuencias de su obrar. Tal incapacidad surge del hecho de que, como se expusiera con anterioridad, en la acción misma confluyen una pluralidad de actores, de modo que resulta imposible que el individuo en su singularidad pueda tener el control total de las consecuencias de su obrar. El perdón y la promesa son las dos alternativas que Arendt encuentra dentro del marco de la acción misma para hacer frente a dichas incapacidades.

\section{I. Dimensión política del mal totalitario}

En esta sección se realizará un análisis de la dimensión política del mal surgido durante el gobierno de los regímenes totalitarios con los conceptos arendtianos de acción, juicio y espacio público como centro de la reflexión. Dichas categorías serán rastreadas y analizadas en cada una de las obras estudiadas con anterioridad (OT y E) con el objetivo de determinar si hay una continuidad en las reflexiones arendtianas respecto a la dimensión política del mal o si, por el contrario, se detectan cambios de postura por parte de Arendt o contradicciones en su pensamiento. 


\section{I.I. La dimensión política del mal en $O T$}

En el prólogo a la primera edición de OT Arendt hace referencia a la crisis que atravesara el ámbito político tradicional, principalmente en su espectro categorial, durante el proceso que devino en el surgimiento de los movimientos totalitarios, al punto de que sus conceptos más representativos quedaron disueltos. En el tomo denominado "Imperialismo", Arendt menciona el surgimiento de la burguesía como clase social que detenta un gran poder económico sin aspirar al poder político. En la descripción arendtiana de esta etapa histórica se puede observar cómo las cuestiones económicas comienzan un proceso de independencia respecto del cuerpo político. Al verse coartado en sus pretensiones expansionistas por las características inherentes al sistema de gobierno vigente, el poder económico de la naciente burguesía se rebeló contra las limitaciones impuestas por las Naciones-Estado. En las colonias, el control era ejercido por la policía y el ejército pero de forma independiente respecto de las instituciones políticas de las cuales dependían en sus Estados de origen. Los territorios conquistados se convirtieron en espacios hostiles para la conformación de nuevos cuerpos políticos en tanto se regían por los mandatos inherentes a la política imperial, a saber: expansión y acumulación de capital ilimitadas. La burocracia, definida por Arendt como el gobierno de una minoría experta sobre una mayoría inexperta, se volvió el agente de gobierno principal en las colonias y las leyes fueron reemplazadas por decretos. Respecto al imperialismo continental, Arendt resaltó el hecho de que se manifestaba por completo hostil a las instituciones políticas vigentes. Esta ideología fue encarnada por los pan-movimientos, conformados por el populacho, los cuales adoptaron del imperialismo de ultramar la forma burocrática de organización y el racismo, en este caso, fundado sobre una concepción fuerte del concepto de "raza", del cual carecía el racismo colonial. Canclini destaca, entre los hechos que propiciaron el advenimiento de los regímenes totalitarios, el auge de lo social, la degradación de la acción asociada a los nacionalismos y la identificación de la ley con la voluntad del soberano (2016, p. 128).

En el último tomo de $O T$, "Totalitarismo", Arendt se refirió al surgimiento de los regímenes totalitarios, los cuales requirieron necesariamente del apoyo masivo para constituirse como fuerzas dominantes. Estas masas estaban conformadas por hombres cuya principal característica era su atomización y su falta de relaciones sociales normales. Los movimientos totalitarios contaron con el apoyo de miembros de los estratos sociales más dispares, desde intelectuales hasta representantes del populacho. Pero entre sus seguidores más aptos en relación con sus intereses y objetivos se encontraban los filisteos, definidos por 
Arendt como aquellos individuos recluidos en sus vidas privadas, amantes de sus familias y abocados íntegramente a sus vidas profesionales. En cuanto a la composición de su forma de gobierno, el terror era su pieza clave y su ley suprema, la voluntad del Führer. El objetivo principal de los regímenes totalitarios era la dominación total de los individuos por lo que la eliminación de la libertad y la espontaneidad inherentes a la constitución básica de todo ser humano se volvió un requisito ineludible. El campo de concentración y exterminio, en tanto tecnología inédita puesta al servicio de los objetivos del movimiento, representaba el grado máximo del horror. En él los seres humanos son reducidos a la superfluidad, impera la soledad y toda posibilidad de acción, pensamiento y juicio propio queda abolida.

En este punto cabe analizar con un grado mayor de profundidad la noción de soledad recientemente mencionada, la cual cobra importancia en este contexto en tanto se encuentra directamente relacionada con la dimensión política del quehacer humano. Arendt, en el capítulo XIII del último tomo de $O T$, realiza una distinción entre los conceptos de aislamiento y soledad. Respecto del primero afirma que remite a esa situación extrema y sin salida en la que se encuentran aquellos individuos a los que se les destruyó la esfera política de sus vidas (Arendt, 1998, p. 380). En este estado no hay posibilidad alguna para el ejercicio ni la actualización de la acción y del poder. Este aislamiento que se vuelve necesario para la puesta en práctica de la actividad productora inherente también al ser humano, se torna insoportable cuando la creatividad, entendida como la capacidad de añadir algo nuevo al mundo, es destruida. Arendt afirma que semejante estado de la humanidad se vuelve una posibilidad cuando todas las esferas de la vida del hombre se conciben como labor, de tal forma que la relación del individuo con el mundo, concebido como artificio humano, también se rompe. El ser humano aislado, anulado en su dimensión política al no encontrar espacio para la acción, es abandonado también por el mundo. Ya no es más reconocido como homo faber sino que es reducido a su condición de animal laborans, en este estado el aislamiento se vuelve soledad.

Arendt sostiene que la soledad es la esencia del terror ejercido por los totalitarismos y cobra su sentido más real y profundo en compañía de los demás. Dicha soledad tuvo como antecedentes directos el desarraigo y la superfluidad a la que fueron sometidas las masas modernas desde la revolución industrial, hecho que se profundizó durante la era imperial y como consecuencia de la destrucción de instituciones políticas y de las tradiciones sociales en el siglo XX. La soledad que fue convirtiéndose en una realidad cotidiana durante los tiempos modernos, preparó el terreno para la consolidación y dominación de los regímenes totalitarios, de ahí su relevancia política. El desarraigo es la precondición de la superfluidad y, de la misma manera, el aislamiento lo es de la soledad. En los campos se materializó esta lógica 
y los prisioneros, no obstante (sobre)vivir en un hacinamiento extremo, se encontraban condenados a la más terrible de las soledades, situación que, a criterio arendtiano, es contraria a los requerimientos mínimos y básicos de la condición humana (1998, p. 380). Al perderse el propio yo, la soledad se torna insoportable pues, a esta pérdida está unida la pérdida del mundo, de la capacidad de pensamiento y experiencia?.

Arendt no utiliza los conceptos de acción, juicio y espacio público en su análisis de la dimensión política de la dominación totalitaria en $O T$ pero de sus reflexiones sobre las medidas tomadas por las autoridades del régimen y sobre la realidad imperante en los campos de concentración, se deriva el hecho de que la capacidad política de los seres humanos fue abolida durante el nazismo. Si por acción se entiende la capacidad humana que acontece entre los hombres, cuya condición es la pluralidad, y por medio de la cual el individuo inicia en el mundo, de manera espontánea, una cadena nueva de acontecimientos, no cabe duda de que esta fue abolida durante el régimen totalitario. La facultad del juicio que remite, en la concepción arendtiana, a la capacidad humana de distinguir el bien del mal, no puede actuar en aislamiento pues se encuentra inmersa en una determinada comunidad que le otorga sentido y logra la imparcialidad sopesando los posibles puntos de vista de los otros por medio de la imaginación. Por todo lo expuesto es evidente, también, que el espacio público en el que se inserta dicha acción, el mundo donde los seres humanos se encuentran e interactúan, fue destruido por el mismo movimiento. Alli donde impera la soledad no hay posibilidad alguna de discurso ni de acción en tanto ambas actividades requieren, necesariamente, de la trama de las relaciones humanas para hacerse efectivas.

En la imposibilidad de ser espontáneos se evidencia la anulación de la libertad, sin la cual la dimensión política del hombre carece de sentido. Esta libertad concebida políticamente no es un fenómeno derivado de la voluntad, pues deriva de la ciudadanía y se da en el marco de las relaciones intersubjetivas (Canclini, 2016, p. 36). La dimensión política del mal totalitario consistió en la anulación de la misma, es decir, en la eliminación de la capacidad humana para la acción, en tanto se aisló a los individuos entre sí para, luego, hundirlos en la desesperación que acarrea la soledad. El espacio público concebido como espacio de aparición y cuya

9 En VE Arendt reflexiona sobre el concepto de soledad en contraposición con la noción de "solitud" y deja de lado el análisis de la relación entre soledad y aislamiento, la cual había sido abordada con anterioridad en el cap. XIII de OT (ver Arendt, 1998, p. 380). Respecto de la soledad, la define como el estado en el que el individuo se encuentra solo en un doble sentido, a saber: está privado de la compañía de los demás y también de la suya propia. La solitud, por su parte, remite a un yo que se hace compañía a sí mismo no obstante encontrarse solo. Esta solitud es la esencia de la vida del espíritu en tanto es la actualización del dos en uno inherente a la actividad del pensamiento (1984, p. 92). 
característica principal es la pluralidad y la igualdad, fue abolido durante el gobierno totalitario nazi.

\section{I.2. La dimensión política del mal en EJ}

Como se mencionara en reiteradas oportunidades, EJ es la crónica de un juicio en la que el foco del análisis está puesto en su figura principal, el imputado. Es por esto que en este apartado cuyo eje reflexivo se centra en la dimensión política del mal, se analizarán las actitudes, los gestos, el testimonio y los hechos llevados a cabo por Eichmann en relación con los conceptos guía propuestos para realizar el mencionado análisis: acción, juicio y espacio público. De manera anticipada podría decirse que la mencionada dimensión de análisis, la política, cobra relevancia en toda reflexión sobre la banalidad del mal por su anulación y no por su ejercicio. Este comentario debe hacerse extensivo a todo estudio sobre el mal totalitario, pues tanto el mal radical como el mal banal son categorías que solo pueden hacerse efectivas en el marco de la abolición del espacio público y, por consiguiente, de la incapacidad para el ejercicio de la acción y de la facultad del juicio.

A modo de recapitulación, cabría afirmar que Eichmann representa la encarnación perfecta del filisteo $y$, en este sentido, cumple con el prototipo del seguidor ideal de todo régimen totalitario. Su principal preocupación giraba en torno a cumplir cabalmente y de manera eficiente el rol inherente a su investidura. En su obediencia a las órdenes recibidas de forma eficaz y sin cuestionamientos radicaba su orgullo y el sentido de su existencia, pues, a su entender, tal era el modo de comportamiento esperado por parte de la sociedad de todo oficial o funcionario del régimen que aspirara a ser respetado y valorado. Estas cuestiones dejan en evidencia que Eichmann, durante el período juzgado, no ejerció su capacidad de acción en sentido arendtiano. En consonancia con esto podría afirmarse que fue una víctima del sistema de gobierno totalitario que, a los efectos de alcanzar la dominación total y haciendo uso del terror, anuló e impidió que se dieran las condiciones necesarias para que acontezca la acción. Sin embargo, si se acepta lo anterior, debería catalogarse de víctimas a todos los miembros y funcionarios del partido y, por consiguiente, los juicios llevados a cabo a los fines de impartir justicia respecto de los crímenes nazis perderían su sentido. Es decir, solo Hitler y los miembros principales del movimiento podrían haber sido juzgados como responsables, cuestión que, como mínimo, desestima la autonomía humana y la capacidad del individuo para autolegislarse y actuar en consecuencia. 
Tener en cuenta la realidad contextual de los delitos juzgados es clave para comprender y juzgar a quienes los cometieron, pero esto no los exime de sus responsabilidades. Arendt se alegra de que exista una institución, la legal, que juzgue a individuos reales y no a sistemas ni tendencias y donde resulta difícil eludir la responsabilidad personal por los actos cometidos (2007b, p. 52). Eichmann se hacía eco de una tendencia generalizada vinculada a la reticencia, por parte de la sociedad en general, a emitir juicios, a criterio arendtiano, por una suerte de temor hacia ellos. Arendt esboza la explicación de que, detrás de la mencionada reticencia a ejercer la capacidad de juicio se encuentra la creencia o sospecha de que los agentes juzgados no eran libres al momento de llevar a cabo los delitos $y$, por consiguiente, tampoco responsables. En lo que respecta a la concepción arendtiana del juicio y su relación con el problema del mal, Benhabib (1996, p. 185) sostiene que el caso Eichmann es, al respecto, paradigmático. Por un lado se encuentra el juicio retrospectivo de cada narrador de los eventos pasados, por otro, el juicio moral de los contemporáneos que tienen a su cargo llevar adelante el proceso legal contra Eichmann y, por último, la completa incapacidad del acusado de ejercer la facultad de juicio.

En lo que se refiere a la banalidad del mal, noción que como ya se mencionara tiene a Eichmann como su principal exponente pero no se reduce a él ${ }^{10}$, no obstante las escasas especificaciones que Arendt brinda al respecto, se puede sostener que las categorías de acción, juicio y espacio público se actualizan en un escenario que excluye necesariamente el surgimiento y la pervivencia del mal banal. La acción, cuya principal característica es la capacidad de iniciar de forma espontánea nuevas cadenas de acontecimientos en el marco de un espacio de aparición compartido y de encuentro con otros no es detentada por el agente del mal banal. Precisamente, una de las notas distintivas de la banalidad del mal es su desconexión casi total con la racionalidad entendida como la capacidad para la reflexión. "Las palabras y el pensamiento son los dos elementos clave respectivamente tanto de la acción política (...) como de la preparación para el juicio (...), el cual a su vez requiere el uso del lenguaje" (llivitzky, 2017, p. 193). Arendt, a lo largo de su crónica del juicio a Eichmann, menciona en diferentes oportunidades las falencias del acusado a la hora de expresarse ante el tribunal, su constante recurrir a frases hechas, eslóganes y clichés, y la renuncia explícita a ejercer su facultad de juicio. Todas estas cuestiones repercuten, directa o indirectamente, en la capacidad que tiene el individuo para actuar en el espacio público.

10 Debe tenerse en cuenta que existe una línea crítica que considera que la noción de la banalidad del mal aplica únicamente a Eichmann. Al respecto cf. Formosa (2007), entre otros. 
Como contraposición a la postura de Eichmann, Arendt menciona el caso del sargento alemán Anton Schmidt, quien fuera ejecutado al descubrirse que brindaba ayuda a los judíos otorgándoles documentación falsa y poniendo a su disposición camiones del ejército. Con este ejemplo Arendt quiere demostrar que era posible, aún en el contexto imperante en la Segunda Guerra Mundial, ejercer el juicio propio y actuar en consecuencia. Es evidente que el sargento Schmidt ejercía su capacidad de reflexión y de diálogo consigo mismo. La interpelación del propio yo, si es escuchada, puede ser insoportable en tanto es continua, constante y sin reparos. En la breve referencia arendtiana al caso del sargento Schmidt se puede percibir cómo se lo erige como el opuesto exacto de Eichmann, tanto desde el punto de vista externo, pues sus acciones fueron opuestas (el primero ayudó y salvó a tantos judíos como le fue posible, el segundo desempeñó un rol fundamental en su aniquilamiento) como desde la interioridad. Schmidt se supo dueño de sus actos y, en consecuencia, responsable. No solo desobedeció a sus superiores sino que se puso al servicio de aquellos que debían ser considerados sus enemigos. Este caso excepcional durante el régimen totalitario nazi es esperanzador a los ojos de Arendt, pues demuestra que el mundo todavía es un lugar apto para que lo habiten los seres humanos.

Beiner (2003) recuerda que Arendt intentaba encontrar una explicación para el mal que se hizo realidad durante los regímenes totalitarios. Es en estrecha relación con esto que la facultad del juicio cobra vital importancia, pues es en la incapacidad detentada por Eichmann para emitir juicios donde Arendt ve la fuente de los peores males en la esfera política. En el seminario que dictara en Chicago, "Basic Moral Propositions", menciona que esta incapacidad o rechazo del ejercicio de la facultad de juzgar no se reduce a Eichmann sino que es un fenómeno típico de la modernidad. Este rechazo del juicio es entendido por Arendt como la incapacidad para elegir los propios ejemplos y la compañía, es en esto en lo que consiste la banalidad del mal, el peor de los peligros que acechan a la humanidad. Estas cuestiones se replican en un debate entre Arendt y Jonas que tuvo lugar en la Universidad de York en 1972. En una de sus intervenciones la pensadora manifiesta que lo que más la atemoriza es el hecho de que muchos individuos están dispuestos a intercambiar un código moral por otro sin que medie la reflexión y el análisis crítico, pues lo que les brinda seguridad no es el contenido de la regla sino el hecho de contar con una norma a seguir. Esto se evidenció en la Alemania nazi donde los ciudadanos respetables obedientes de los viejos valores fueron los primeros en adoptar el nuevo código moral impuesto por el nazismo sin mayores inconvenientes.

El mal banal prolifera en un ámbito en el que los individuos se encuentran atomizados, abocados a sus propios intereses, preocupados por la consecución de sus objetivos y el 
bienestar personal. Al ser estas sus motivaciones, la acción no puede acontecer en tanto la dimensión política del ser humano se encuentra obstruida. Tal obstrucción radica en la despreocupación y el descuido a la hora de fomentar el crecimiento de un espacio público compartido en el cual se asienta la posibilidad de crear poder junto a los otros. A modo de recapitulación, si se vuelve al análisis de la dimensión política del mal en $O T$, se podría decir que Eichmann, tanto en los hechos juzgados como en su modo de comportase durante el juicio, es la encarnación de los efectos de la anulación total de la dimensión política del ser humano. En este sentido cabría decir que las reflexiones arendtianas respecto a lo acontecido durante el nazismo en el plano político ofrecen una continuidad entre OTy EJ en tanto el caso Eichmann funge como ejemplo particular de lo analizado por Arendt en $O T$ en un nivel general.

\section{La noción de juicio y el "Post Scriptum" de EJ}

Como menciona Beiner (2003), el hecho concreto que motivó a Arendt a reflexionar no solo sobre el pensamiento sino también sobre la facultad de juzgar fue su presencia como cronista en el juicio a Eichmann en 1961. Esta experiencia la enfrentó con una realidad que la llevó a cambiar de opinión respecto a la naturaleza del mal totalitario. De su caracterización del mal acaecido durante el régimen nazi como un mal radical pasa a postular su controvertida noción de la banalidad del mal. "Me impresionó la manifiesta superficialidad del acusado, que hacía imposible vincular la incuestionable maldad de sus actos a ningún nivel más profundo de enraizamiento o motivación" (Arendt, 1984, p. 14). Arendt (2003b) sostiene que fue la irreflexión lo que llevó a Eichmann a cometer crímenes horrendos, pues durante el juicio quedó en evidencia que sus actos no fueron motivados por intenciones malvadas ni por el odio extremo hacia sus víctimas sino que fueron en respuesta a las órdenes recibidas y a su afán por ser bien considerado por los rangos más importantes del movimiento nazi. La enseñanza que, según Arendt, se deriva de la experiencia del juicio que tuvo lugar en Jerusalén es que la irreflexión puede ser mucho más peligrosa y causar daños mucho mayores que los peores instintos del ser humano.

En lo que se refiere a los juicios de la posguerra, Arendt pone el acento en que dejaron en evidencia una cuestión moral fundamental, "a saber, la naturaleza y función del juicio humano" (Arendt, 2003a, p. 175). Puesto que durante el régimen totalitario nazi los crímenes eran legales, es decir que, en muchos casos, la ilegalidad radicaba en negarse a cometerlos, resultaba imprescindible que los individuos fueran capaces de distinguir el bien del mal, lo justo de lo 
injusto, valiéndose de su propio juicio y no de un código de normas impuesto. No obstante, menciona que la opinión pública está convencida de que quien no formó parte de los hechos a juzgar no está capacitado para emitir juicios. Al respecto Arendt aclara que, de ser esto cierto, la administración legal de justicia carecería por completo de sentido, cuestión con la que, sin lugar a dudas, la mencionada opinión pública no estaría de acuerdo.

Como se puede observar en lo que respecta a la facultad de juzgar, Arendt considera, al momento de escribir el "Post Scriptum", que el no ejercerla fue lo que llevó a Eichmann a convertirse en uno de los principales responsables del advenimiento de un tipo de mal nunca antes experimentado. En el análisis de este caso en particular se puede observar cómo Arendt está convencida de que quien debe juzgar los hechos y actuar en consecuencia es quien se encuentra directamente inmerso en el devenir de los acontecimientos.

\section{Conclusión}

La concepción arendtiana de la dimensión política del ser humano responde a la relación del individuo con los otros en el espacio público. En este espacio de aparición acontece el encuentro entre seres diferentes, y cuya pluralidad respetan, que detentan su capacidad de acción en cada dar inicio espontáneamente a una cadena nueva de acontecimientos. Esta dinámica política de la vita activa inherente, en cuanto a capacidad, a todo ser humano, se ve impedida de actualizarse durante el imperio de los regímenes totalitarios. Como se expusiera durante el análisis de la dimensión política del mal en $O T$, la degradación de los individuos a seres superfluos llevada a cabo por el régimen nazi como principal objetivo para lograr la dominación total tuvo como consecuencia directa y necesaria la obturación de la capacidad de acción propia de los seres humanos. El espacio público que tiene lugar en el mundo creado por los hombres y en cuyo ámbito se despliega la acción humana fue destruido.

En el caso de $E J$ el análisis de la dimensión política del mal ofrece una continuidad respecto del de $O T$ en tanto las referencias y menciones a los hechos llevados a cabo por Eichmann como a su comportamiento durante el juicio y a los rasgos de su personalidad son el ejemplo de lo que ocurre con los seres humanos que viven bajo el imperio de los regímenes totalitarios. La incapacidad de ejercer el juicio propio, de ser espontáneo y actuar en consonancia con las reflexiones del pensamiento que surgen del diálogo del yo consigo mismo se hizo evidente durante el proceso llevado a cabo en Jerusalén. Debe tenerse presente que Arendt insiste en la posibilidad de no dejarse arrastrar por la situación imperante, no obstante su dificultad innegable, y ejercer la capacidad de análisis y reflexión inherente a todo ser 
humano. Es decir que las condiciones de vida creadas por los totalitarismos del siglo $X X$ no son determinantes y no pueden fungir de excusa a la hora de dar cuenta del obrar personal. En este sentido podría afirmarse la continuidad de las reflexiones arendtianas en lo referente a la anulación de la capacidad humana para la acción y en la eliminación del espacio público en las dos obras analizadas.

El análisis de la dimensión política del mal totalitario revela una continuidad a lo largo de las reflexiones arendtianas matizadas con algunos puntos conflictivos. En OT Arendt describe cómo y bajo qué condiciones las posibilidades de acción y juicio propio fueron obturadas durante el régimen totalitario nazi de la mano de la eliminación del espacio público. Quedó demostrado, con el experimento puesto en práctica por el nazismo, que los individuos, aunque se encuentren apiñados unos al lado de otros y conformen una multitud, la soledad es el rasgo que impera $y$, al hacerlo, se ve impedido tanto el surgimiento de la acción como la construcción de un espacio público.

La acción, el juicio y el espacio público cobran realidad en el marco de una comunidad compuesta por una pluralidad de seres que interactúan entre sí, la cual reconoce y otorga valor a sus acciones y discursos. En este sentido cobra relevancia la reflexión que Arendt expone en OT al final del tomo "Imperialismo" sobre las perplejidades de los Derechos del Hombre, en la cual hace mención, precisamente, al grave peligro que acarrea la pérdida de comunidad. "La calamidad que ha sobrevenido a un creciente número de personas no ha consistido entonces en la pérdida de derechos específicos, sino en la pérdida de una comunidad que quiera y pueda garantizar cualesquiera derechos. Solo la pérdida de la comunidad misma le arroja de la Humanidad (Arendt, 1998, p. 248). En OT Arendt da cuenta del proceso de pérdida por el que atraviesa la comunidad política en la que reina la reciprocidad $y$, en este sentido, la igualdad. Dicho proceso culmina en la realidad totalitaria donde impera el aislamiento, la soledad y la capacidad de acción y juicio es abolida.

En EJ Arendt encuentra la encarnación de lo anteriormente analizado en OT. Eichmann es incapaz de acción y juicio propio y, por el hecho de obedecer todas y cada una de las órdenes recibidas por la única razón de que encarnaban la voluntad del Führer, es decir, la ley, justifica y entiende su obrar en el marco de la teoría moral kantiana. Lo que desconoce, sin embargo, es que en la ética kantiana la ley emana de la propia razón del individuo y nunca viene dada desde fuera. En el mencionado reporte arendtiano cobra relevancia la falta de reflexión y de pensamiento que Arendt descubre en el obrar del imputado, rasgo fundamental a la hora de comprender la noción de banalidad del mal. Es en este punto donde la relevancia política de la 
facultad de pensar cobra peso. El pensar, la facultad contemplativa por excelencia, adquiere valor político, a criterio arendtiano, en época de crisis. Pero esta capacidad humana no se mantiene incólume respecto de la vita activa, es decir, se ve afectada por las condiciones materiales que la sustenta. Arendt sostiene que el pensamiento es posible siempre y cuando los hombres vivan en condiciones de libertad política (2009, p. 349) y son precisamente dichas condiciones las que se vieron afectadas directamente durante el régimen totalitario nazi. Eichmann es el prototipo del funcionario no reflexivo que delega en la autoridad de la ley (una ley externa a él) la toma de decisiones y, por lo tanto, no se siente responsable de su obrar. La única decisión que toma es la de obedecer, decisión que defiende y de la que se siente orgulloso hasta el final de su vida.

Para finalizar y en conexión directa con lo anterior, es fundamental tener presente que el nazismo eliminó la pluralidad de la esfera de las relaciones humanas $y$, al hacerlo, indirectamente obturó la capacidad de pensamiento inherente a todos los seres humanos. En tanto la concepción arendtiana de la facultad de pensar alude al diálogo del yo consigo mismo, el individuo, al encontrarse en soledad (ya no en solitud), se ve impedido de todo pensamiento. Esta consecuencia, concluyó Arendt luego de conocer a Eichmann, demostró ser nefasta no solo en este caso en particular sino en su capacidad infinita de propagación y su capacidad de daño. "Por desgracia, y contrariamente a lo que se suele creer de la proverbial e independiente torre de marfil de los pensadores, no existe ninguna otra capacidad humana [la capacidad del pensamiento] tan vulnerable, y de hecho es mucho más fácil actuar que pensar bajo un régimen tiránico" (Arendt, 2009, p. 349).

El pensamiento crítico, ese que cobra relevancia en época de crisis y que puede intuirse como la única alternativa que encuentra Arendt para prevenir ante la amenaza constante del mal, se caracteriza por su carácter vincular, por lo que en aislamiento y en total ausencia de los otros sería incapaz de ser ejercido. Sin embargo, desde la dimensión política se puede sostener que el caso excepcional que mencionara Arendt en EJ, el del sargento Schmidt, da cuenta de que la capacidad de reflexionar y de emitir juicios sin parámetros externos puede manifestarse más allá de las dificultades, no así la acción, la cual se ve por completo anulada ante la imposibilidad del establecimiento y la constitución del espacio público. Queda por resolver si dicho individuo [el sargento Schmidt] tuvo o no conflicto personal o dudó antes de decidirse a desobedecer y ayudar a quienes debía eliminar. Esta cuestión no carece de importancia en tanto Arendt sostiene que los pocos que se mantuvieron fieles a sí mismos, que dialogaron consigo mismos y se atrevieron a juzgar, no tuvieron conflicto de conciencia y no dudaron a la hora de decidir de qué lado estaban. Eichmann es la contracara generalizada (en tanto la gran 
mayoría de la sociedad alemana se comportó, a nivel moral, de la misma manera) del ejemplo esperanzador que Arendt viera en el sargento Schmidt. Por las decisiones que tomó (Eichmann), debía ser juzgados, aunque no se sintiera responsables. Es decir, Arendt no duda en ningún momento de la legitimidad de ninguno de los procesos legales analizados en sus obras pero se cuestiona al respecto. ¿Por qué deben ser juzgados y cómo deben llevarse a cabo dichos juicios? ¿Debe crearse una reglamentación ad hoc? ¿Qué rol debe desempeñar el contexto a la hora de la sentencia? Estas preguntas no pueden ser respondidas en esta investigación pero abren la puerta hacia nuevas indagaciones que serán abordadas en futuros trabajos.

\section{Referencias}

Arendt, H. (1984). La vida del espíritu. El pensar, la voluntad y el juicio en la filosofía y en la política. Centro de Estudios Constitucionales.

Arendt, H. (1997). ¿Qué es política? Paidós.

Arendt, H. (1998). Los orígenes del totalitarismo. Taurus.

Arendt, H. (2003a). Conferencias sobre la filosofía política de Kant. Paidós.

Arendt, H. (2003b). Eichmann en Jerusalén. Un estudio sobre la banalidad del mal. Lumen.

Arendt, H. (2006). Sobre la revolución. Alianza.

Arendt, H. (2007a). Algunas cuestiones sobre filosofía moral. En Responsabilidad y juicio (pp. 75-150). Paidós.

Arendt, H. (2007b). Responsabilidad personal bajo una dictadura. En Responsabilidad y juicio (pp. 49-74). Paidós.

Arendt, H. (2009). La condición humana. Paidós.

Beiner, R. (2003). Hannah Arendt y la facultad de juzgar. En H. Arendt, Conferencias sobre la filosofía política de Kant (pp. 157-270). Paidós.

Benhabib, S. (1993). La paria y su sombra: sobre la invisibilidad de las mujeres en la filosofía política de Hannah Arendt. Revista Internacional de Filosofía Política, 2, 2I-35.

Benhabib, S. (1996). The Reluctant Modernism of Hannah Arendt. Sage.

Bernauer, J. (1985). On Reading and Mis-reading Hannah Arendt. Philosophy \& Social Criticism, I/ (I), I-34.

Bernstein, R. (2004). El mal radical: una indagación filosófica. Lilmod.

Canclini, R. (2016). Un mundo para la acción. Subjetividades políticas y ley en Hannah Arendt. EdiUNS.

Canovan, M. (1992). Hannah Arendt. A Reinterpretation of Her Political Thought. Cambridge University Press.

Di Pego, A. (2007). Las concepciones del mal en la obra de Hannah Arendt. Crítica de la modernidad y retorno a la filosofía. Al Margen, Número Especial: Hannah Arendt, pensadora en tiempos de oscuridad, I-I5. 
Formosa, P. (2007). Is Radical Evil Banal? Is Banal Evil Radical? Philosophy \& Social Criticism, 33 (6), 7I7-735.

Hilb, C. (2015). "Por eso, Sr. Eichmann, debe Ud. colgar". De Eichmann en Jerusalén a los "Juicios" en Argentina (reflexiones situadas). African Yearbook of Rhetoric, 6 (I), 3-I3.

llivitzky, M. (20I7). Del "mal radical” a la "banalidad del mal". Teseo.

Jonas, H. (2000). Actuar, conocer, pensar. La obra filosófica de Hannah Arendt. En F. Birulés (Comp.): Hannah Arendt y el orgullo de pensar (pp. 23-40). Gedisa.

Pendas, D. (2007). "Eichmann in Jerusalem", Arendt in Frankfurt: The Eichmann Trial, the Auschwitz Trial, and the Banality of Justice. New German Critique, 100, 77-109.

Rabotnicof, N. (2005). En busca de un lugar común. El espacio público en la teoría política contemporánea. Instituto de Investigaciones Filosóficas-UNAM.

Sahui Maldonado, A. (2002). Hannah Arendt. Espacio público y juicio reflexivo. Signos filosóficos, 8, 24I-263.

Villa, D. (1999). Conscience, the Banality of Evil, and the Idea of a Representative Perpetrator. En Politics, Philosophy, Terror. Essays on the Thought of Hannah Arendt (pp. 39-60). Princeton University Press.

Young-Bruehl, E. (1993). Hannah Arendt. Edicions Alfons el Magnànim-IVEl. 